\title{
Social waves in giant honeybees (Apis dorsata) elicit nest vibrations
}

\author{
Gerald Kastberger • Frank Weihmann • Thomas Hoetzl
}

Received: 6 March 2013 /Revised: 30 April 2013 /Accepted: 2 May 2013 /Published online: 31 May 2013

(C) The Author(s) 2013. This article is published with open access at Springerlink.com

\begin{abstract}
Giant honeybees (Apis dorsata) nest in the open and have developed a wide array of strategies for colony defence, including the Mexican wave-like shimmering behaviour. In this collective response, the colony members perform upward flipping of their abdomens in coordinated cascades across the nest surface. The time-space properties of these emergent waves are response patterns which have become of adaptive significance for repelling enemies in the visual domain. We report for the first time that the mechanical impulse patterns provoked by these social waves and measured by laser Doppler vibrometry generate vibrations at the central comb of the nest at the basic (='natural') frequency of $2.156 \pm 0.042 \mathrm{~Hz}$ which is more than double the average repetition rate of the driving shimmering waves. Analysis of the Fourier spectra of the comb vibrations under quiescence and arousal conditions provoked by mass flight activity and shimmering waves gives rise to the proposal of two possible models for the compound physical system of the bee nest: According to the elastic oscillatory plate model, the comb vibrations deliver supra-threshold cues preferentially to those colony members positioned close to the comb. The mechanical pendulum model predicts that the comb vibrations are sensed by the members of the bee curtain in general, enabling mechanoreceptive signalling across the nest, also
\end{abstract}

Communicated by: Sven Thatje

Electronic supplementary material The online version of this article (doi:10.1007/s00114-013-1056-z) contains supplementary material, which is available to authorized users.

G. Kastberger $(\bowtie) \cdot$ F. Weihmann $\cdot$ T. Hoetzl

Department of Zoology, University Graz, 8010 Graz,

Austria

e-mail: gerald.kastberger@uni-graz.at

F. Weihmann

e-mail: frank.weihmann@uni-graz.at

T. Hoetzl

e-mail: thohoe@aon.at through the comb itself. The findings show that weak and stochastic forces, such as general quiescence or diffuse mass flight activity, cause a harmonic frequency spectrum of the comb, driving the comb as an elastic plate. However, shimmering waves provide sufficiently strong forces to move the nest as a mechanical pendulum. This vibratory behaviour may support the colony-intrinsic information hypothesis herein that the mechanical vibrations of the comb provoked by shimmering do have the potential to facilitate immediate communication of the momentary defensive state of the honeybee nest to the majority of its members.

Keywords Giant honeybee - Apis dorsata $\cdot$ Bee curtain . Shimmering $\cdot$ Defence waves $\cdot$ Comb vibrations $\cdot$ Elastic plate model $\cdot$ Mechanic pendulum model $\cdot$ Frequency spectrum $\cdot$ Colony-intrinsic communication

\section{Introduction}

Giant honeybees (Apis dorsata) are one of the most ancient honeybee species (Ruttner 1988; Oldroyd and Wongsiri 2006; Kastberger et al. 2011a). They nest in the open (Seeley et al. 1982) and are, therefore, especially exposed to predators, such as mammals (Kastberger 1999), birds (Seeley et al. 1982; Kastberger and Sharma 2000) and wasps (Seeley et al. 1982; Kastberger et al. 2008, 2010). Their most prominent defensive behaviour against such threats is shimmering, which generates repetitive social waves with anti-predatory impact (Kastberger et al. 2008, 2010, 2012, 2013; Weihmann et al. 2012). In shimmering, bees at the nest surface, predominantly younger cohorts (Lerchbacher et al., submitted) in the quiescent regions peripheral to the mouth zone (Kastberger et al. 2011b), show simultaneous and cascaded actions (Schmelzer and Kastberger 2009) whereby their abdomens are flipped upwards at an angle between $20^{\circ}$ and $120^{\circ}$ (Kastberger et al. 2011a, b). These 
individual mechanical actions of surface bees emerge to a visual display of waves which have the potential to repel or at least scare external predators such as wasps (Kastberger et al. 2008) or vertebrates (Kastberger et al. 2013).

The mechanical expression of shimmering, represented in particular by its motion components in the $z$-direction (i.e. towards and away from the comb; Kastberger et al. 2011b) is still unclear in its ultimate goals. However, two mechanistic viewpoints can here be proposed:

First, mechanical cues provoked by shimmering may be important for the rapidness of the wave propagation across the nest. Alternative strategies eventually processed by visual cues among adjacent neighbours, utilising stigmergic (Grasse 1959; Kastberger et al. 2013) principles, such as bucket-bridging (Kastberger et al. 2012) or eavesdropping (Peake 2005; Jones et al. 2011), would be much slower by one or two orders of magnitude than those which are actually observed in shimmering (Kastberger et al. 2012, 2013). The saltatoric principle of wave propagation (Kastberger et al. 2013), which may speed up the wave from a basically bucket-bridging process by a factor of 3 , is supposed to be associated to the visual input of threatening cues and to the mechanical effects of the shimmering waves in the bee curtain.

Second, shimmering could benefit the entirety of the colony by allowing colony-intrinsic propagation of information across the nest via its mechanical expression of wave components (Kastberger et al. 2011b). This proposition is summarized by the colony-intrinsic information hypothesis which predicts that the shimmering waves may also disseminate information about the momentary defence state of the colony to those nest members which do not participate in this collective action. Shimmering-passive cohorts usually make up more than $90 \%$ of the colony and comprise curtain bees in the surface and subsurface layers on both sides of the nest.

In accordance with this proposition of a potential colonyintrinsic spread of information across the nest, the mechanical components of the shimmering process should affect the centrally positioned comb of the nest. The comb is the only architectural structure of an $A$. dorsata nest with the capacity to rapidly bridge information from the threatened to the nonthreatened nest side. Therefore, we examined whether shimmering does produce vibrations at the comb. To qualify as signals which could potentially be utilised for intra-colonial communication, mechanical vibrations of the comb should exceed at least the perception threshold of Western honeybees (Sandeman et al. 1996) which can be estimated at dislocation amplitudes of $>9 \mu \mathrm{m}$ in the low-frequency range $(<10 \mathrm{~Hz})$.

\section{Material and methods}

\section{Experimental site}

The experimental nests of giant honeybees (A. dorsata) were located at a hotel site in Sauraha, Chitwan, Nepal (at the border of the Chitwan National Park). Preliminary experiments had been performed in February 2009, but in November 2010, a single nest had been selected for a much broader in-depth investigation. This nest was attached to blocks of concrete making up a balcony of the hotel. The nest had a hemicyclic form, measured $83 \times 60 \mathrm{~cm}$ (width $\times$ height), was approximately 2 weeks old and could have had a weight of $30 \mathrm{~kg}$ (see Seeley et al. 1982 and the 'Results' section). In the first days of observation, the comb was covered only by a single layer of honeybees, but a few days later, the colony had achieved a multilayer cover due to the progressive hatching of young bees (Fig. 1).

\section{Video recording}

The experimental nest was filmed with a high-definition (HD) video camera (Panasonic HVX 200) from a distance

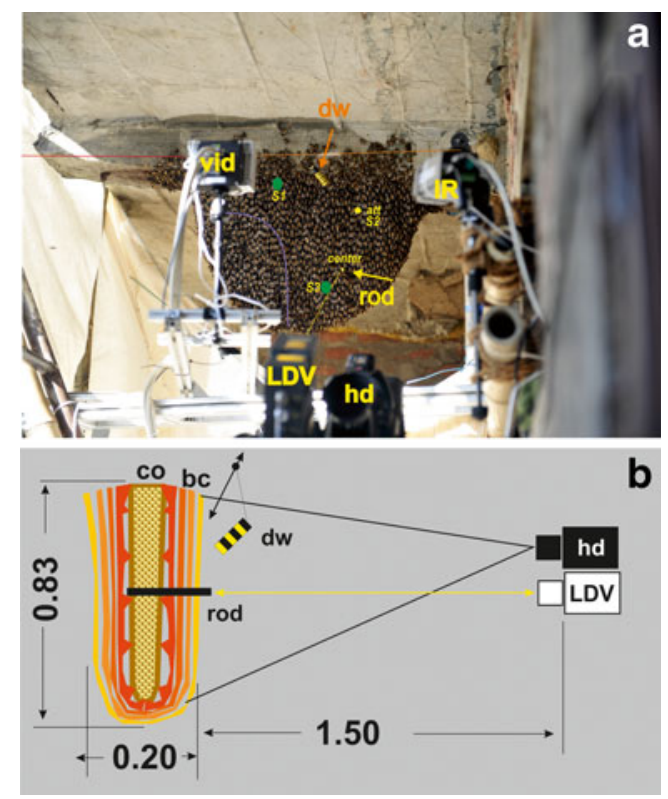

Fig. 1 Measurement set-up of the experimental A. dorsata nest. a $h d$ HD video camera, vid black and white video camera, $I R$ infrared camera, $L D V$ laser Doppler vibrometer, with the yellow straight line as the ray of the laser; the dummy wasp ( $d w$, see orange arrow) was moved under computer control from the left to the right side of the nest, the orange line at the upper rim of the nest gives the wire of the cable car device by which the dummy had been moved. The mouth zone was positioned to the left of the violet curve. b Schematics of the set-up from the side view, with a perpendicular cross-section through the nest; distances in metres; a wooden rod (diameter, $8 \mathrm{~mm}$; length, $10 \mathrm{~cm}$ ) was stuck through the bee curtain $(b c)$ into the comb $(c o)$ at position centre or alternatively at positions $\mathrm{S} 1-3$ with $\mathrm{S} 2=a t t$, and a white plate was mounted on the front plane of the rod to reflect the laser beam 
of $1.5 \mathrm{~m}$, whereby the camera angle covered the whole nest (Fig. 1). This distance provided an undistorted view and was also distant enough to keep the colony undisturbed, as the bees accepted the camera as just a landmark. The recordings were made at 50 frames per second (FPS) with a resolution of $1,280 \times 720$ pixels.

\section{Laser vibrometry}

A wooden rod $(8 \mathrm{~mm}$ thick and $10 \mathrm{~cm}$ long with a weight of $1.28 \mathrm{~g}$ ) was stuck into the comb, with one end protruding slightly out the surface of the bee curtain. A piece of white paper was glued to its plane end to serve as a reflector for the laser beam of the laser Doppler vibrometer (abbreviated further on as 'LDV'; Polytec PDV 100; Fig. 1). In this way, the directional $z$-component of the movement of the comb (towards and away from the nest surface) was detected by the velocity values assessed by the Doppler phase shift between the emission and reflection of the laser signal. These data were assessed with the wooden rod positioned at selected points:

For the spectrum analysis, we used the positions S1-2 (14 November 2010) and included mass flight, pure quiescence and presentation of the dummy wasp. For further evaluations of the correlation between shimmering and comb vibrations, we used the position att, $10 \mathrm{~cm}$ below the attachment zone (experiments: 9 November 2010), and the position centre, central between the right-hand border of the mouth zone and the right-hand rim of the nest (experiments: 10 November 2010), at least $30 \mathrm{~cm}$ below the attachment zone (Fig. 1).

The LDV had a resolution of $<0.05 \mu \mathrm{m} / \mathrm{s}$. The raw data were produced by the LDV in sample intervals of $20 \mu \mathrm{s}$ (resulting in a sampling frequency of $f_{\mathrm{s}}=1 /\left(20 \times 10^{-6}\right)[\mathrm{Hz}]$ ), processed by MATLAB through a low-pass Butterworth IIR filter with a cut-off frequency of $f_{\mathrm{LP}}=250 \mathrm{~Hz}$ (with $f_{\mathrm{LP}}=$ $\left.0.01 \times f_{\mathrm{s}} / 2\right)$ and displayed in data streams, frequency spectrograms (abscissa: experimental time; ordinate: frequency components; $z$-axis: power spectral density [PSD]) and single-sided Fourier spectra (abscissa: frequency components; ordinate: LDV signal [in millimetres per second]). The raw Butterworth filtered LDV data streams were offsetcorrected and integrated for the calculation of dislocation values scaled in millimetres.

\section{Dummy wasp stimulation}

We stimulated the experimental colony by presenting a dummy wasp which was a cuboid Styrofoam block measuring $8 \times 2 \times 2 \mathrm{~cm}$ covered with yellow and black stripes (Fig. 1; Kastberger et al. 2011a, b, 2012, 2013). It was suspended beneath a horizontal wire fixed above the nest attached by a flexible thread, allowing the dummy to swing.
It was moved by a miniature computer-driven cable car device at a constant velocity $(0.1-0.5 \mathrm{~m} / \mathrm{s})$ along the horizontal wire, $20 \mathrm{~cm}$ in front of the nest near its upper attachment zone. This stimulation method was chosen to mimic a free-flying wasp scanning in front of the nest and has regularly provoked shimmering (Kastberger et al. $2011 \mathrm{a}, \mathrm{b})$. The dummy wasp (dw) was presented to the colony by drawing it from the parking site at the upper left side of the nest to the right side and back again (Fig. 1). Automated pinpointing of the dummy's location was achieved by assessment of its motion (see the next section) using predefined templates. This allowed the identification of the dummy regardless of the viewing angle and the associated light conditions (Fig. 2) and the assessment of its gravity position (dummy: $x_{\mathrm{dw}}, y_{\mathrm{dw}}$ ) during the whole presentation cycle.

Experimental sessions and assessment of shimmering motions

During shimmering, cohorts of bees in the surface layer of the nest flip their abdomens upwards in an angle which may exceed $90^{\circ}$. Synchronized and cascading processes emerge to a Mexican wave-like pattern. A light-emitting diode (LED) placed next to the comb was used to signal the start of the recording of the oscillations of the central comb. A video-recorded LED flash allowed synchronisation between video recording, image analysis and vibrometry. Each of the experimental sessions $\left(n_{\mathrm{s}}=23\right)$ lasted for 6,292 frames ( $125.84 \mathrm{~s}$ ) and included two phases: (a) an arousal phase, in which the colony had been stimulated by the presentation of the moving dummy wasp (Fig. 1), and (b) a subsequent quiescent phase, in which the dummy had been halted at its parking site at the upper left side of the nest (Fig. 1). The video films were re-formatted as sequences of jpg images using the Avid Media Composer editing software (Avid Technology, Inc.) in order to enable the pixel-based luminance analysis (ImagePro Plus, Media Cybernetics). Motion patterns of dummy (dw) and shimmering (sm) were quantified in terms of differences in pixel luminance $(\Delta \mathrm{lum})$ between two sequential frames (Figs. 2 and 3; Supplementary Movie 1). Minor to no change in luminance values $(\Delta \operatorname{lum} \leq 5)$ represented the 'motionless' state and were displayed as 'black' in the differential image. Change in luminance values of $\Delta \mathrm{lum}>5$ signalled 'movement'; they were segmented (Kastberger et al. 2011a, b, 2012, 2013) as 'white' spots and charted regarding the coordinates of their gravity points (shimmering: $\mathbf{x}_{\mathrm{sm}}, \mathbf{y}_{\mathrm{sm}}$ ) and their pixel areas per frame. The sum of white areas in a difference image of the nest surface was taken separately for dummy and shimmering $\left(A_{\mathrm{sm}}\right)$ as the value for motion activity at the time the second sequential frame was captured (Fig. 2). 
Fig. 2 Automated detection of the dummy wasp position. Four scenes under various lighting conditions and angles taken from real video images of the dummy wasp. The colour of the dummy was partially matched in the video film (marked as red areas in a) and segmented (marked as white areas in b); for comparison, see HD images of the dummy above the attachment zone of the nest in Figs. 1 and 3
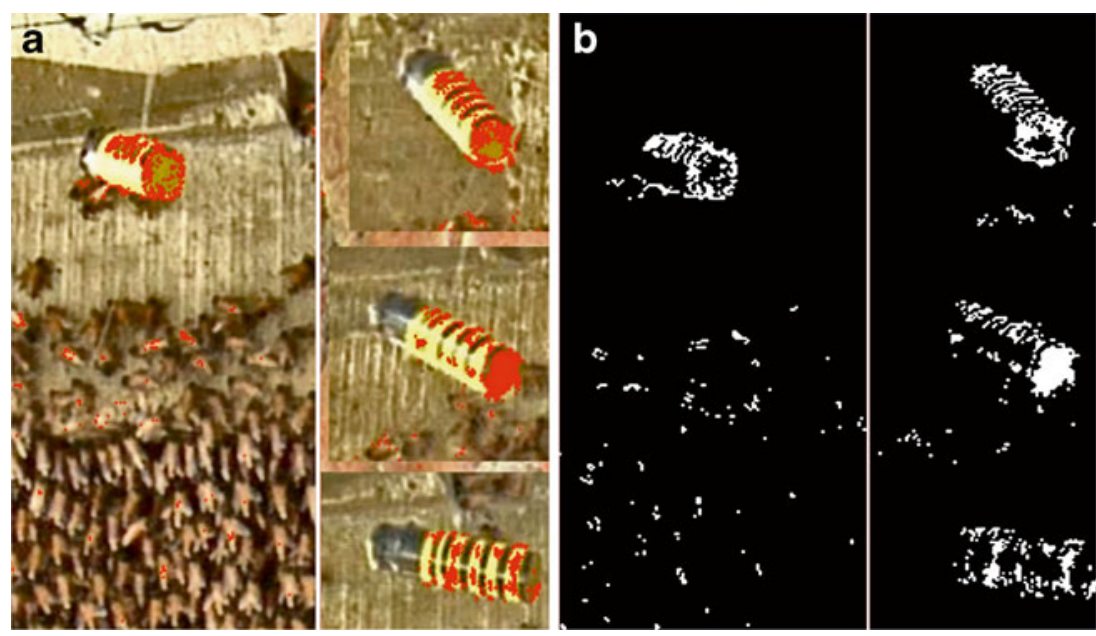

Comparison of shimmering activity and comb vibration

For each experimental session, the motion patterns of the dummy (dw) and of shimmering (sm) at the nest surface were monitored together with the displacements of the central comb $\left(D_{\mathrm{c}}\right)$ during the arousal (ar) and quiescent (qu) phases (Fig. 4; Supplementary Movie 1). The two 'oscillatory' signals, the shimmering activity and the comb vibration, exhibited different base ('natural') periods $\left(T_{\mathrm{sm}}, T_{\mathrm{c}}\right)$ and base ('natural') frequencies $\left(f_{\mathrm{sm}}, f_{\mathrm{c}}\right)$, respectively. Therefore, the momentary amplitudes of the signals $\left(A_{\mathrm{sm}}\right.$, $\left.A_{\mathrm{c}}\right)$ could not be directly compared. We established a demodulation procedure by maxima enveloping by searching for peaks in the course of the amplitudes of both signals $\left({ }^{\max } A_{\mathrm{sm}},{ }^{\max } A_{\mathrm{c}}\right)$ within running intervals $\left(\left[f_{i-2}, f_{i+2}\right]\right.$, with $f_{i}$ as the frame being examined) and by connecting the detected peaks by straight lines (Fig. 4c, e). The enveloped data of both signals $\left({ }^{\mathrm{env}} A_{\mathrm{sm}},{ }^{\mathrm{env}} A_{\mathrm{c}}\right)$ were then correlated for every time point $t_{i}$ (at the frames $f_{i}$ ) throughout both experimental phases. For the basic statistics (mean $\pm \mathrm{SE}$ ), the data were stepped according to the intervals of the dummy presentation cycles in the arousal phase and in 5-s intervals for the subsequent quiescent phase (see vertical intercept lines in Fig. 4).

\section{Results}

Shimmering activity dislocates mass in the bee curtain

The mass of a giant honeybee (A. dorsata) nest is determined by two assembly parts (Ruttner 1988; Kastberger 1999; Kastberger et al. 2011a, b), comb and bee curtain. The comb is built of wax cells with watery contents of larvae, honey and pollen. A single cell of the comb with a diameter of $6 \mathrm{~mm}$ and a length of $25 \mathrm{~mm}$ (values based on own observations) has a volume of $7.065 \times 10^{-7} \mathrm{~m}^{3}$ which sums up for the comb with a double layer of cells (assuming a mean mass density of $0.80 \mathrm{~kg} / \mathrm{L}$ due to the part of the wax) to $40 \mathrm{~kg} / \mathrm{m}^{2}$ comb area.

The bee curtain consists of multiple layers of bees. In addition to the honey stores in specified comb areas in the genus Apis (Ruttner 1988), giant honeybees possess individual honey provisioning (own observations) as a social property which makes them particularly robust against short-term food shortages. Most of the shimmering-active curtain bees contain a mass of $100 \mathrm{mg}$ or more of watery honey in their stomach (Oldroyd and Wongsiri 2006; Kastberger et al. 2011b), which accounts for the majority of the abdomen mass. Assuming that a single bee has a body weight of $150 \mathrm{mg}$, the bee curtain of a nest of 50,000 bees would weight approximately $7.5 \mathrm{~kg}$. Based on these estimates, large giant honeybee nests could achieve a mass of more than $M_{\text {nest }}=50 \mathrm{~kg}$ (Ruttner 1988).

Colony members as honey storers become much heavier in their abdomens compared to their counterbalancing heads. This aspect is particularly important for the shimmering action, whereby surface bees flip their abdomens (abd) up at angles ranging from $20^{\circ}$ to $120^{\circ}$, depending on their arousal level (Kastberger et al. 2011a, b). From a physics viewpoint, each bee acts here as a torsion pendulum (Kastberger et al. 2011b) with an acentric axis and two disparate masses on both sides of the rotation centre, the upward head and the downward abdomen. Abdomen flips cause a single oscillation or multiple oscillations of the mass of the abdomen in a curved motion. Mass inertia produces a reaction force, which initially presses the individual bee with the thorax towards the nest, but consecutively, the thrust of the pendulum mass initiates a centrifugal force which is directed away from the comb (see a movie of an abdomen-flipping model bee in Kastberger et al. 2011b). Both motion components affect the $z$-direction, which can be defined regarding the inertial system of the nest as towards and away from the comb (which defines the $z$ direction). In this way, a single bee would provoke a centrifugal force of $F_{z}=1.266 \mathrm{mN}$ (Eq. 1), assuming an 


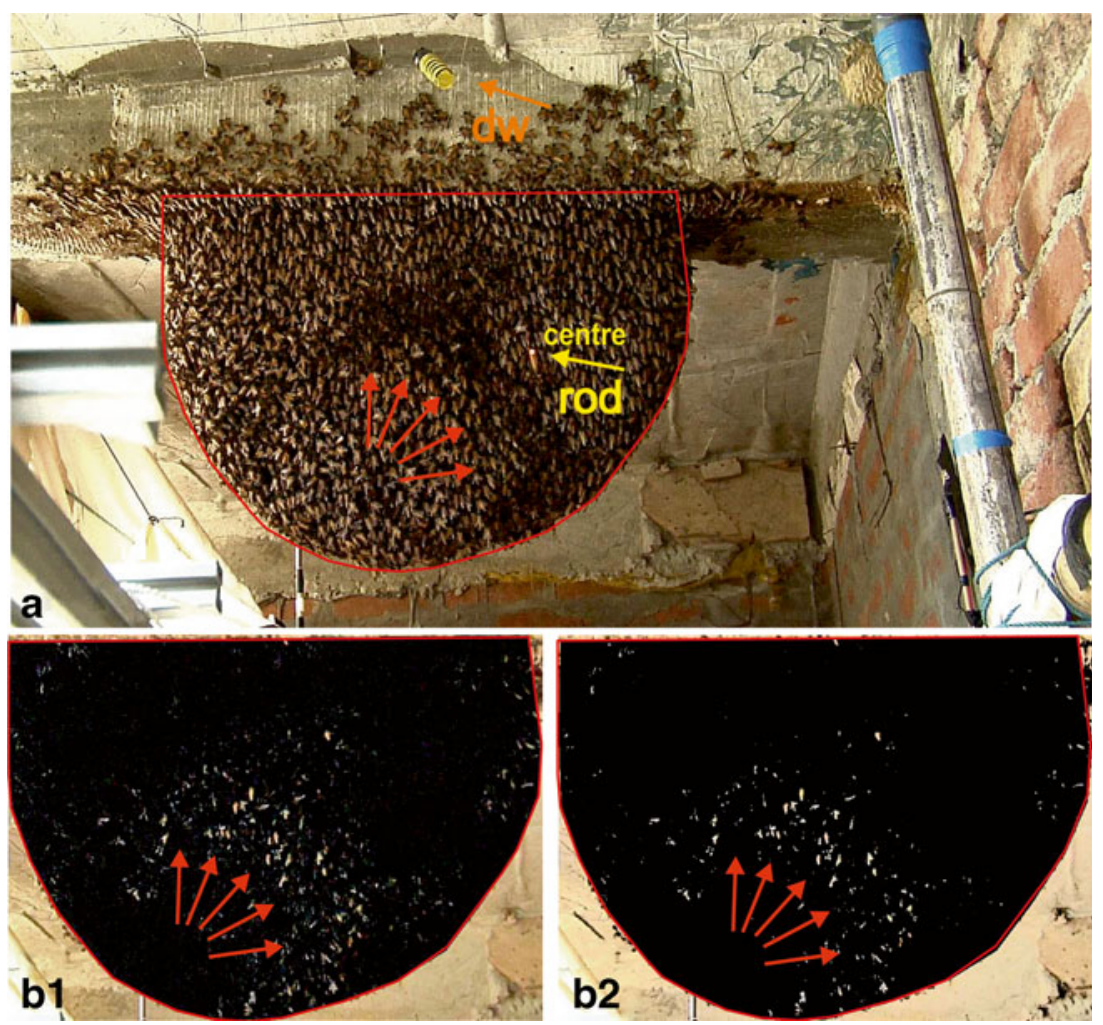

Fig. 3 Detection of motion activity at the nest surface. a Original HD image of the nest with the dummy wasp ( $d w$, see arrow) from 1 of 50 experimental sessions. The wooden rod for the LDV measurement (see small yellow circle marked by the yellow arrow) was fixed in the comb (by pushing it through), here at position centre (see Fig. 1). On the front plane of the rod, the original bright reflection spot of the laser beam is visible. The darker shadow-like areas in the plane of the nest (in front of the red arrows) indicate the presence of a shimmering wave which spread in the image hemi-cyclically from bottom left to top right. The red line around the nest gives the area of interest (AOI) in which

abdomen mass $\left[M_{\mathrm{abd}}\right]$ of $100 \mathrm{mg}$ of honey and the respective flipping properties (angle $\left[\ominus_{\mathrm{abd}}\right], 90^{\circ}$; duration $\left[\Delta t_{\mathrm{abd}}\right]$, $80 \mathrm{~ms}$; radius of abdomen length $\left[l_{\mathrm{abd}}\right], 10 \mathrm{~mm}$ ):

$$
\begin{aligned}
F_{z} & =M_{\mathrm{abd}} \times \omega_{\mathrm{abd}}{ }^{2} \times l_{\mathrm{abd}}, \text { with } \omega_{\mathrm{abd}} \\
& =\ominus_{\mathrm{abd}} / \Delta t_{\mathrm{abd}} \text { as angular velocity }
\end{aligned}
$$

In the collective action of shimmering (Seeley et al. 1982; Kastberger et al. 2011a, b) in which hundreds of surface bees are synchronised and cascading within a fraction of a second, the centrifugal forces of the shimmering-active surface bees may total up to more than $1 \mathrm{~N}$ and pull the subsurface layers of the bee curtain away from the comb (Kastberger et al. 2011a). For an A. dorsata nest, this magnitude of force is powerful enough to shift a significant mass of the bee nest for a fraction of a second to an observable extent. Under this mechanical condition, a giant honeybee nest might be considered as a driven physical pendulum (see Online Resource 1). This is even enhanced by the fact that the mechanical perturbation caused by the concerted wave- motion detection was processed by image analysis technique. b Differential luminance images of the nest (AOI only), achieved by pixelwise subtraction of frames $\left(\operatorname{lum}\left[f_{i}\right]-\operatorname{lum}\left[f_{i-1}\right]\right)$, revealing the motionactive surface bees at time $t_{i}$ as bright pixel areas on the black background; $\mathbf{b}_{\mathbf{1}}$ gives the differences in pixel luminance as grey shades (black: $\Delta$ lum $=0$; white: $\Delta$ lum $=255), \mathbf{b}_{2}$ shows the supra-threshold changes in luminance (black: $\Delta$ lum $\leq 5$; white: $\Delta$ lum $>5$ ) quantifying motion by segmented pixel areas (Kastberger et al. 2011a, b; compare Fig. 2b)

like patterns of abdominal flips occurs asymmetrically at only this side of the bee curtain at which the surface bees had been threatened by the visual cue.

\section{Shimmering activity provokes comb vibrations}

In the experiments presented in this paper, two phases of the nest are distinguished (Fig. 4; see Online Resource 2/ Movie 1): the arousal phase, in which the dummy wasp was presented in subsequent cycles provoking shimmering waves (Fig. 4a), and the quiescent phase, in which the dummy stayed positioned at the parking site (see the 'Material and methods' section). Motion activity at the nest surface was low in quiescent phases (Figs. 4, 5 and 6), but rose significantly during arousal in general, such as during mass flight activity (Kastberger et al. 1996) with diffuse, unsynchronized locomotion, or in shimmering activity, in which the abdomens predominantly of surface bees display coordinated, repetitive and, therefore, portioned motions of patterns over time (Kastberger et al. 2011a, b; Fig. 4b). All 


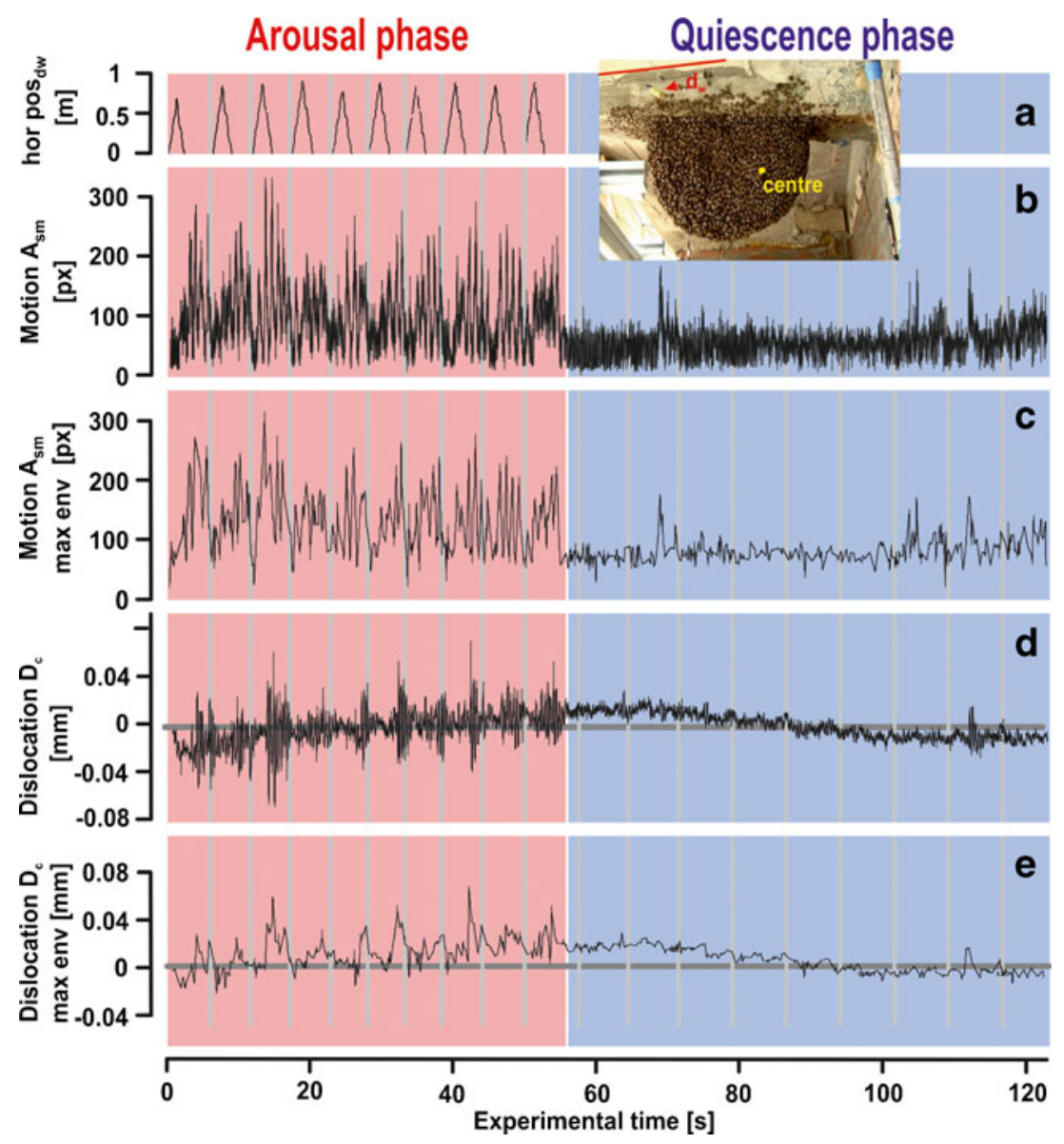

Fig. 4 Motion at the nest surface and comb vibrations in the arousal (pink background) and quiescence (blue background) phases of a single experimental session. a The horizontal position of the dummy wasp (hor $\operatorname{pos}_{\mathrm{dw}}$ ) over time during ten passes across and back in the front of the nest (which defined the arousal phase in the experiment) from position $0 \mathrm{~m}$ at the left side to position $1 \mathrm{~m}$ at the right side as depicted in the images of Figs. 1 and 3. b Time course of motion activity due to shimmering $\left(A_{\mathrm{sm}}\right)$ at the surface of the experimental nest scaled in pixel area (see Fig. $3 \mathrm{~b}_{2}$ ). The peak performance was caused by the movement of the dummy wasp (pictured in Fig. 2). c Envelope

these motions of the curtain bees provoke mass shifts which give rise to associated vibrations at the comb (Fig. 4d).

Generally, shimmering waves are produced by collective decision-making of the surface bees, whereby the natural repetition rate and the motion strength of the shimmering waves (Kastberger et al. 2008, 2011a, b) depend on the arousal level of the participating surface bees. We observed waves at a repetition rate of $\mathrm{wps}_{\mathrm{sm}}=0.957 \pm 0.030 \mathrm{~Hz}$ $\left(N_{\text {wav }}=1,287\right.$ waves in $1,361 \mathrm{~s}$ recording time, with wps as waves per second). The sequences of comb vibrations showed, particularly in the arousal phases, a rhythm in their modulation similar to that of the associated shimmering waves (Fig. 4b, d). This coincidence convincingly indicates that the comb oscillations were incited through the driving force of the shimmering process. The sinusoid oscillations at the comb had base frequencies of $\mathrm{pps}_{\mathrm{c}}=2.156 \pm 0.042 \mathrm{~Hz}$ function of the maximal values of the motion activity $A_{\mathrm{sm}}$ shown in $\mathbf{b}$ (max env $A_{\text {sm }}$, see command 1). d Vibrations scaled as dislocation $\left(D_{\mathrm{c}}\right)$ over time of the central comb in millimetres, as assessed by LDV with the reflective end of the rod as target at the centre position of the nest (see inset). e Envelope function of the maximal values of the vibrations shown in $\mathbf{d}$ (max env $D_{\mathrm{c}}$, see command 1$)$. The grey vertical lines in ae define the interval limits in which correlations between shimmering and vibration activity (see Fig. 5) were calculated (see also Supplementary Movie 1)

( $N_{\mathrm{p}}=2,887$ periods in $1,341 \mathrm{~s}$; with pps as periods per second) which are more than double the average repetition rate of shimmering waves.

In Fig. 5, five experimental sessions exemplify the comb vibrations displayed by oscillograms, spectrograms and frequency spectra of original LDV velocity data (see the 'Material and methods' section). The first session (Fig. 5a) refers to the basically quiescent condition at position S1 (Fig. 1) near the attachment zone. In this session, small shimmering waves happened which had been released by colony-intrinsic reasons. Two frequency bands are documented in the comb vibration, one at the basic frequency of slightly more than $2 \mathrm{~Hz}$, as calculated previously, and a second band at roughly $6 \mathrm{~Hz}$.

The second session (Fig. 5b) refers to the main experimental condition investigated in this paper in which the 


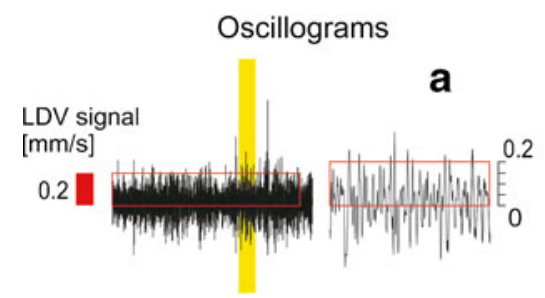

Spectrum Spectrogram
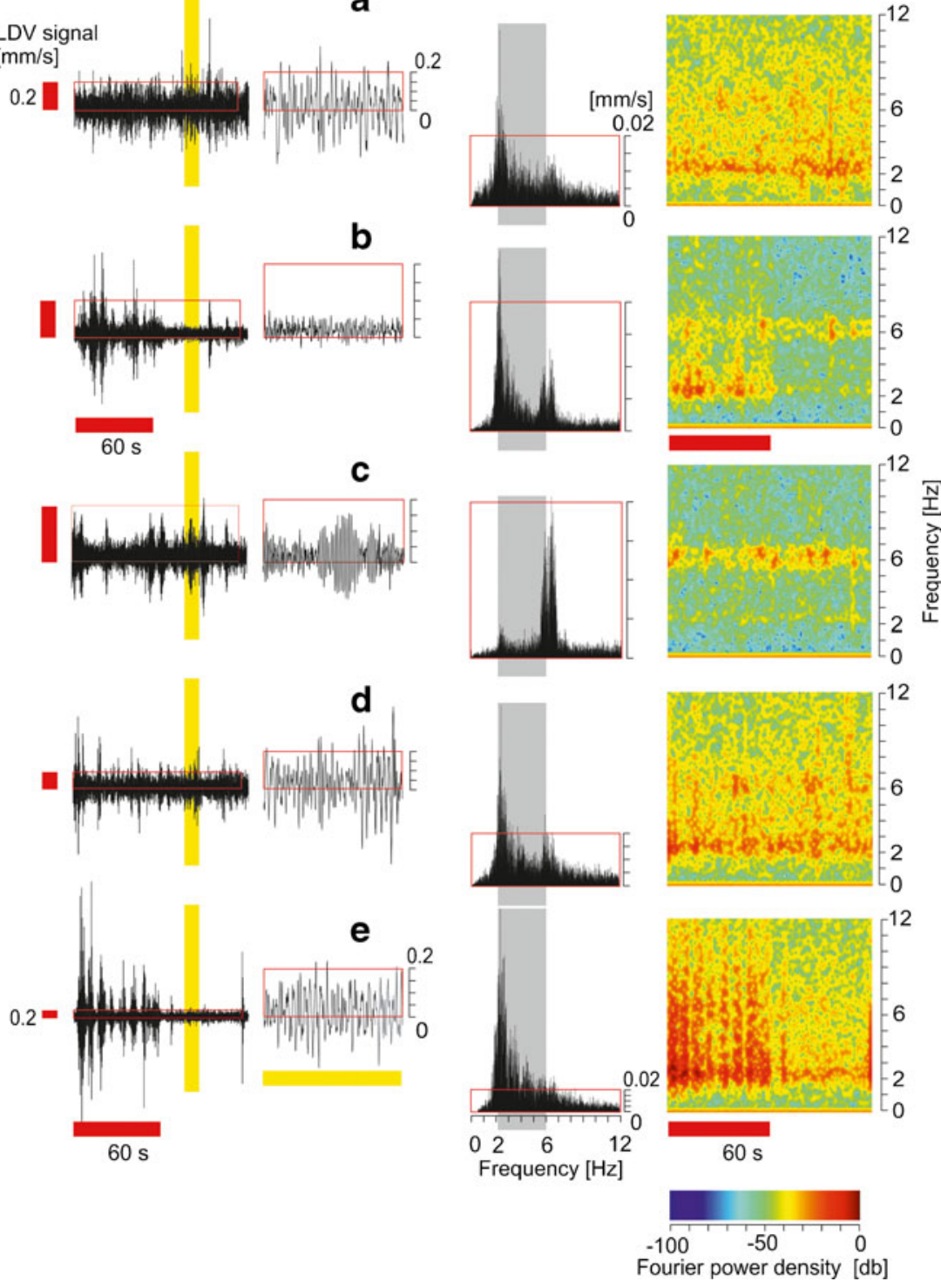

Fig. 5 LDV signals of the comb under different experimental conditions. a Quiescent conditions after the mass flight activity, LDV signals recorded at position S1 (Fig. 1); the dummy wasp was at its parking site. b The dummy wasp was presented for $60 \mathrm{~s}$ (see time scale as red horizontal bar), LDV measurement at position S1. c Mass flight activity without the presentation of the dummy wasp, LDV measurement at position S1. d Quiescent conditions without the presentation of the dummy wasp, LDV signals recorded at position S2 (Fig. 1). e The dummy wasp was presented for $60 \mathrm{~s}$ (see time scale as red horizontal bar), LDV signals recorded at position S2. 'Oscillograms' panels, leftside panels refer to LDV oscillograms (ordinate $[A]$ : velocity in

millimetres per second) of the whole experimental session (abscissa, $125 \mathrm{~s}$ ), right-side panels refer to $10 \mathrm{~s}$ (from 80 to $90 \mathrm{~s}$ of the original session, as documented by the position and width of the vertical yellow bar). 'Spectrum' panels refer to frequency spectra of those sessions documented in the 125-s oscillograms; abscissa: frequency range in hertz; ordinate: amplitude parameter (velocity in millimetres per second). 'Spectrogram' panels: abscissa: experimental time; ordinate, frequency; $z$-axis, PSD from -100 to $0 \mathrm{db}$; PSD $=10 \log 10 \mathrm{ABS}\left(A_{i} /\right.$ $\left.A_{0}\right)^{2}$ ), with $A$ [velocity in millimetres per second] as the amplitude of the Fourier coefficients; see scale of colour codes

presentation of the dummy wasp gave rise to shimmering waves in the arousal phase, while in the post-presentation phase, the colony returned to quiescence. In this session, comb oscillation is displayed on both frequency bands, whereas it becomes clear that the shimmering waves provoked oscillations at the lower band, while in the post-presentation phase, these lower band activities terminated while the small

oscillations at the $6-\mathrm{Hz}$ band still continued. There are two reasons why these comb oscillations provoked by shimmering waves (Fig. 5b) are much smaller than those under Fig. 5e. First, the shimmering waves happened mostly at nest regions other than at position S1 (which was not in the centre of the shimmering patterns), and second, the position S1 was near the attachment zone of the nest. 

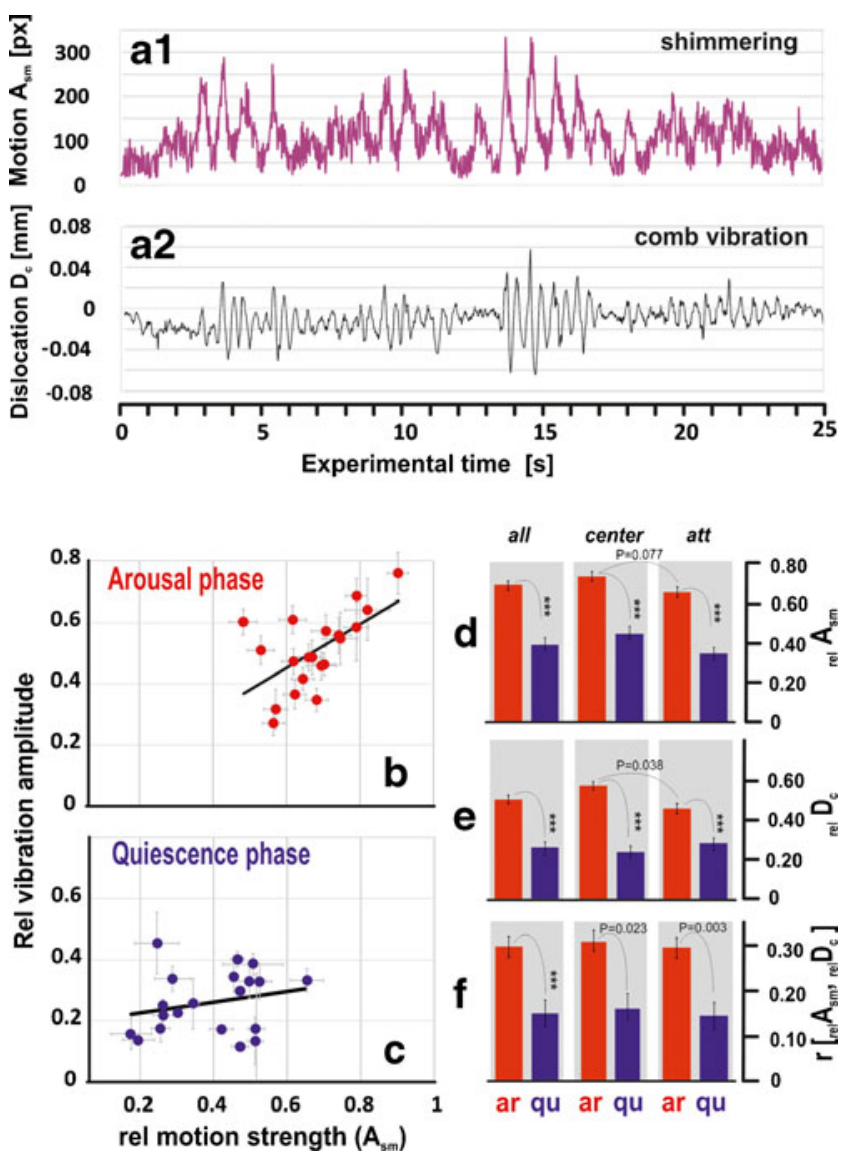

Fig. 6 Correlation of the comb vibrations and the shimmering activity. For measurement at the position centre, samples of motion activity at the nest surface are shown during shimmering $\left(\mathbf{a}_{1}\right)$ and the corresponding vibrations at the comb $\left(\mathbf{a}_{2}\right)$. b, c Abscissa, motion strength $\left({ }_{\mathrm{rel}} \mathrm{S}_{\mathrm{m}}\right)$; ordinate, dislocation per $0.02 \mathrm{~s}$ : ${ }_{\text {rel }} D_{\mathrm{c}}$ of vibrometer signals in the arousal (ar, red) and quiescence (qu, blue) phases; for every experimental session $\left(n_{\mathrm{s}}=21\right)$, the envelope data of comb vibrations and shimmering motions per frame were correlated. Full circles arithmetical means, horizontal and vertical bars SEMs; regression functions of the mean values: arousal phase $\left({ }_{\mathrm{rel}} D_{\mathrm{c}}=0.080+0.676 \mathrm{~s}_{\mathrm{m}} ; R^{2}=0.413\right)$; quiescence phase $\left({ }_{\mathrm{rel}} D_{\mathrm{c}}=0.192+0.176 \mathrm{~s}_{\mathrm{m}} ; R^{2}=0.0549\right)$. d-f Comparison between arousal and quiescent phases: motion strength at the nest surface rel $A_{\mathrm{sm}}$ (d), comb vibration as relative dislocation ${ }_{\mathrm{rel}} D_{\mathrm{c}}(\mathbf{e})$ and correlation coefficients $r$ [rel $A_{\mathrm{sm}}$, rel $D_{\mathrm{c}}$ ] (f) of the means $\left(n_{\mathrm{s}}=21\right)$ at all positions and at the positions centre $\left(n_{\mathrm{s}}=9\right)$ and att $\left(n_{\mathrm{s}}=12\right)$; vertical black bars indicate SEMs; statistics: $* * * P<<0.01$ ( $t$ test)

The third session (Fig. 5c) refers to a period of mass flight activity in which the colony turns into a general state of arousal (Kastberger et al. 1996). Here, locomotor behaviour at the nest surface is combined with heavy flight activity, whereby bees start from the outer layers of the bee curtain and return to the nest some minutes later. In this state, the colony is in turmoil, revealing a characteristic diffuse mechanical activity of locomotor actions and small shimmering waves provoked by returning bees (Kastberger et al. 2011a). The striking difference here to all other samples of Fig. 5 is that the comb oscillations are dominantly represented at the frequency band at $6 \mathrm{~Hz}$. This preference could be characteristic for the driving force as recruited under mass flight activity. However, the velocities of the comb oscillations are here at a low level compared to those at position S3 (Fig. 5d, e).

The fourth sample session (Fig. 5d) refers again to quiescent conditions without the presentation of the dummy wasp as documented under Fig. 5a. Also, here, small 'spontaneous' shimmering waves happened and the comb oscillations are reflected at both frequency bands. However, the vibrations reveal a much higher intensity (as displayed in the oscillograms and in the spectrum), which is obviously caused by the greater distance of position S3 (Fig. 1) from the attachment zone of the nest.

Lastly, session 5 (Fig. 5e) refers to position $\mathrm{S} 2$ and to the sequence of two phases, the arousal phase, in which shimmering waves were elicited by the presentation of the dummy wasp, and the subsequent quiescence phase, without the presence of the dummy. The shimmering-provoked comb oscillations reveal a broad frequency band with a clear peak at slightly above $2 \mathrm{~Hz}$, while in the quiescent phase, both frequency bands were better contrasted (compare Fig. $5 \mathrm{~d}$ ). The shimmering-induced oscillations were quite intense, which is due to the fact that the measurement was taken from position S2 which was located near the main path of the shimmering waves and near the lower rim of the nest.

These vibration spectra of the compound physical system of the nest reveal two strikingly constant frequency bands: the low band of slightly above $2 \mathrm{~Hz}$ can be plausibly interpreted as the natural frequency of this compound system consisting of the comb and bee curtain because it is factually independent regarding the frequency performance from the driving forces, which may be provoked by shimmering waves (Figs. 4 and $5 \mathrm{~b}, \mathrm{e}$ ) or by the mass flight activity (Fig. $5 \mathrm{c}$ ). Both arousal states chosen differ in their time profiles of the driving forces: shimmering waves are rhythmic and strong and the mass flight activity provides more stochastic and much weaker influence. Nevertheless, in the frequency spectra, two prominent bands are visible, at $>2$ and $6 \mathrm{~Hz}$, which is slightly more than double of the base frequency (Fig. 5a-e).

The samples in Fig. 5 let us assume that the driving forces of shimmering waves and mass flight activity feed their energy into different frequency bands: shimmering waves regard the low band of slightly above $2 \mathrm{~Hz}$ and mass flight activity regards the higher band at $6 \mathrm{~Hz}$. The fact that both frequency bands can be detected under both, quiescent and arousal, conditions, though at different intensities and at different locations, supports the view that the compound system of the comb and bee curtain functions as an elastic plate oscillator.

Correlation of comb oscillations with shimmering waves

Both periodic processes, the comb oscillations and the shimmering waves, differed in their basic frequencies (Fig. 4). For correlation, time-dependent power levels of both signals 
were compared throughout the experimental sessions frame by frame, estimated by peak enveloping (see Fig. 4), by collecting the arithmetical means $\pm \mathrm{SE}$ of the strength levels of the shimmering signals $\left(A_{\mathrm{sm}}\right)$ and of the vibration $\left(A_{\mathrm{c}}\right)$ in stepped intervals $(\Delta t=0.02$, FPS $=50 \mathrm{~Hz})$. The amplitude of the vibration between the two time points is further on termed as dislocation $\left(D_{\mathrm{c}}\right)$.

The two enveloped data sets $\left(n_{\exp }=21\right.$ experiments; $n_{\text {int }}=$ 132,321 time intervals of $0.02 \mathrm{~s}$ ) correlated positively (for regression functions, see Fig. 6). The comb oscillations showed under arousal conditions due to shimmering waves significantly $(P<0.001$, Student test) larger dislocations than under quiescent conditions (arousal: $D_{\mathrm{c}}=7.230 \pm 0.573 \mu \mathrm{m}$ per $0.02 \mathrm{~s}$ frame interval, which equals to $D_{\mathrm{c}}=0.3099 \pm$ $0.0286 \mathrm{~mm} / \mathrm{s}, n_{\mathrm{s}}=388$ dummy wasp sessions; Fig. 6a; quiescence: $D_{\mathrm{c}}=3.489 \pm 0.283 \mu \mathrm{m}$ per $0.02 \mathrm{~s}$, which equals to $D_{\mathrm{c}}=$ $0.1745 \pm 0.142 \mathrm{~mm} / \mathrm{s}, n_{\mathrm{s}}=150$ post-arousal sessions; Fig. $6 \mathrm{~b}$ ).

Spatial characteristics of the physical excitability of the comb

The two comb positions (centre and att; Figs. 1 and 6) represent, under the preposition of a physical pendulum (see Online Resource 1 and the 'Discussion' section), two sample distances taken from the pivotal axis. The basic frequencies in the arousal phase were slightly above $2 \mathrm{~Hz}$ (position centre, $2.112 \pm 0.063 \mathrm{~Hz} ; n_{\mathrm{p}}=1,779$ oscillation cycles in $842 \mathrm{~s}$; position $a t t, 2.225 \pm 0.034 \mathrm{~Hz} ; n_{\mathrm{p}}=1,108$ periods in $\left.499 \mathrm{~s}\right)$ and did not significantly differ $\left(P=0.131\right.$, Student test; $\left.n_{\exp }=21\right)$ between both positions. The enveloped amplitudes of oscillations ( ${ }^{\text {env }} A_{\text {sm }},{ }^{\text {env }} D_{\mathrm{c}}$; see the 'Material and methods' section) were related per session to the maximal value to compensate for differences in the recording conditions in the experimental sessions. The dislocations of comb vibration $\left({ }_{\mathrm{rel}} D_{\mathrm{c}}\right.$; see Eqs. $2 \mathrm{a}, 2 \mathrm{~b}$, and $2 \mathrm{c}$ ) under arousal were markedly higher at position centre $\left(n_{\exp }=9\right)$ than at position att $\left(n_{\exp }=11 ; P=0.059\right.$, Student test; Fig. 6d):

$$
\begin{aligned}
& \begin{aligned}
D_{\mathrm{c}}\left[t_{i-1}, t_{i}\right] & =\Delta A_{\mathrm{c}} /(0.02)[\mathrm{mm} / \mathrm{s}] \text { with } \Delta A_{\mathrm{c}} \\
& =\left(A_{\mathrm{c}}\left[t_{i}\right]-A_{\mathrm{c}}\left[t_{i-1}\right]\right) \text { for every inter }- \text { frame interval } \Delta t_{f f} \\
& =t\left[f_{i}\right]-t\left[f_{i-1}\right] \text { at } 50 \mathrm{fp}
\end{aligned} \\
& \text { rel } D_{\mathrm{c}}=D_{\mathrm{c}}\left[t_{i-1}, t_{i}\right] / \max D_{\mathrm{c}}\left[t_{i-1}, t_{i}\right]
\end{aligned}
$$

$A_{\mathrm{c}}\left[t_{i-1}, t_{i}\right]=\Delta A_{\mathrm{c}} /\left(0.02^{2}\right)\left[\mathrm{mm} / \mathrm{s}^{2}\right]$

The shimmering activities in the two series of experiments concerning the measurement positions centre and att had similar strength levels ( $P=0.077$, Student test; Fig. 5 c), which allows comparison of the associated dislocations. This consistency is also expressed by the arousal factor $F_{\text {ar }}$ (Eq. 3 ; centre: $F_{\mathrm{ar}}=1.64 ;$ att: $F_{\mathrm{ar}}=2.05 ; P=0.83$, chi- square test) which denotes a similar proportion between the motion levels in the subsequent experimental phases of arousal (ar) and quiescence (qu):

$F_{\mathrm{ar}}={ }_{\mathrm{rel}} A_{\mathrm{sm}}[\mathrm{ar}] / \mathrm{rel} A_{\mathrm{sm}}[\mathrm{qu}]$

As expected, the correlation coefficients between ${ }_{\text {rel }} D_{\mathrm{c}}$ values of comb vibration and the $\operatorname{rel} A_{\mathrm{m}}$ values of motion strength at the nest surface yielded higher $(P<0.05$, Student test) magnitudes under arousal than under quiescence and had also similar proportions regarding both measurement positions (Fig. 6e).

Assessment of cycle-based dislocation and acceleration spectra of comb vibrations

To compensate for obvious noise effects (see Online Resource 1) and to prove perspectives for potential communication goals, the dislocation and acceleration spectra have to be considered regarding the basic ('natural') period of the vibration cycles of the comb $\left(T_{\mathrm{c}}=1 / f_{\mathrm{c}}\right)$ under shimmering (arousal) conditions which was assessed as $\mathrm{pps}_{\mathrm{c}}=2.156 \pm$ $0.042 \mathrm{~Hz}$ (see previous section). For that, we determined the peaks and sinks of the time integral of the LDV signal with an automated method according to the algorithm of command 1:

Command 1

$$
\begin{aligned}
& \text { IF }\left(A_{i}-A_{i-3}\right)>A_{\text {threshold }} \text { AND }\left(A_{i}-A_{i+3}\right)>A_{\text {threshold }} \\
& \text { THEN PEAK }\left[f_{i}\right]=\text { TRUE } \\
& \text { IF }\left(A_{i-3}-A_{i}\right)>A_{\text {threshold }} \text { AND }\left(A_{i+3}-A_{i}\right)>A_{\text {threshold }} \\
& \text { THEN SINK }\left[f_{i}\right]=\text { TRUE }
\end{aligned}
$$

checking every frame $f_{i}$ for exceeding the respective threshold conditions with $\mathrm{A}_{\text {threshold }}=5 \mu \mathrm{m}$.

This procedure factually introduced a digital low-pass filter (with $T_{\mathrm{c}}>20 * \Delta t_{\mathrm{ff}}$ ) and documented the dynamics at the basic frequency of the comb. It allowed the assessment of dislocation (or of acceleration) values per oscillation cycle of the comb and utilized the $\left|\Delta A_{\mathrm{p}, \mathrm{s}}\right|$ values between a peak and the subsequent sink (or between a sink and the subsequent peak) for calculating the respective dislocations $D_{\mathrm{vc}}$ within vibration cycles (Eq. 4):

$$
\begin{aligned}
D_{\mathrm{vc}} & =\left|\Delta A_{\mathrm{p}, \mathrm{s}}\right| / \Delta t_{\mathrm{c}} \text { and } a_{\mathrm{c}} \\
& =\left|\Delta A_{\mathrm{p}, \mathrm{s}}\right| / \Delta t_{\mathrm{c}}{ }^{2} \text { with }\left|\Delta A_{\mathrm{p}, \mathrm{s}}\right| \\
& =\left|A_{\mathrm{PEAK}}-A_{\mathrm{SINK}}\right| \text { and } \Delta t_{\mathrm{vc}}=T_{\mathrm{c}}=1 / f_{\mathrm{c}} ; f_{\mathrm{c}} \\
& =2.114 \mathrm{~Hz} \text { (see the previous paragraphs) }
\end{aligned}
$$

The resulting spectra of displacement and acceleration reveal (Fig. 7) that, under arousal conditions, $51.08 \%$ of 
vibration cycles of comb oscillations exceeds the sensory threshold of honeybees (calculated after Sandeman et al. 1996). The spectra of Fig. 7 strongly differ $(P \ll 0.01$, Student test) for both positions under arousal (centre: $n_{\mathrm{vc}}=$ 3,$160 ;$ att: $n_{\mathrm{vc}}=3,416$ ) and between arousal and quiescence (centre: $n_{\mathrm{vc}}=3,215$; att: $n_{\mathrm{vc}}=2,895$ ), but not under quiescence. The data suggest that the spectra are primarily shaped by differences in amplitudes of the vibrations and not by different noise levels (see Supplementary Text 1).

\section{Discussion}

Communicative impact of substrate-borne vibrations

The shimmering process in giant honeybees (Kastberger et al. 2008, 2011a, 2012, 2013) exemplifies the principle that fast and accurate spreading, gathering and sharing of information entails the success of group-living species (Evans et al. 2007). In an A. dorsata colony, the collective of curtain bees form for the purpose of repelling enemies (Kastberger et al. 2008, 2011a, b) adaptive patterns in the visual, pheromone and mechanical domains. Visual cues trigger and flexibly adjust the Mexican wave-like shimmering process (Kastberger et al. 2010, 2011a, 2013; Schmelzer and Kastberger 2009). Nasonov scenting (Kastberger et al. 1996) modulates the coherence and strength of the shimmering process. Mechanical traits, synchronised and cascading as displayed by the waves in the visual domain, are produced by the abdomen-lifting actions (Kastberger et al. $2011 \mathrm{a}, \mathrm{b})$ of bees primarily in the surface layer. These mechanical activities cause mass shifts in the nest which take place within fractions of a second (Kastberger et al. 2011a, 2012, 2013) and are asymmetrical regarding the nest geometry, as shimmering primarily concerns the threatened nest side. However, the forces associated with these mass shifts affect the whole nest and thus also the centrally positioned comb. The present paper questions here whether the shimmering-active surface bees do have the capacity to establish comb vibrations which are supra-threshold (Sandeman et al. 1996) cues to provide intra-colony information for the entirety of the nest mates (Figs. 1, 4, 5, and 6).

Use of substrate-borne vibrations for communicative goals is well known in arthropods. It has been described in sap-sucking bugs when signalling presence, attraction, alarm or defence between group members (Cocroft 1996; Cocroft and Rodriguez 2005; Hartbauer 2010) and also in termites (Evans et al. 2007), sawflies (Carne 1962) and caterpillars (Claridge 1985; DeVries et al. 1993; Cocroft and Rodriguez 2005; Yack et al. 2001; Fletcher et al. 2006). Social hymenoptera use vibration of substrates as signals, particularly for recruiting foragers (ants: Roces et
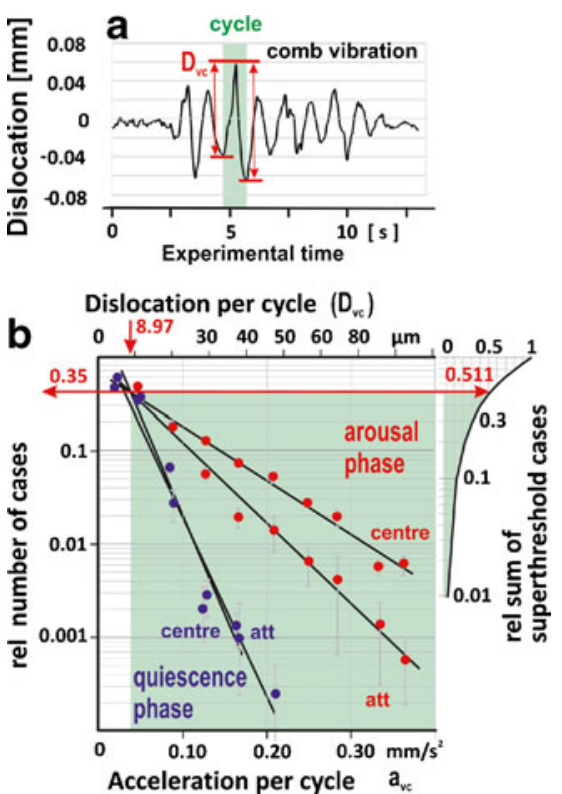

Fig. 7 Cycle-based dislocation spectra at the comb in the experimental A. dorsata nest as provoked by shimmering waves. a Definition of dislocation $\left(D_{\mathrm{vc}}\right)$ per cycle of comb vibration $\left(f_{\mathrm{vc}}=2.114 \mathrm{~Hz} ; T_{\mathrm{vc}}=\right.$ $0.473 \mathrm{~s}$ ) as the distance [in micrometres] between a sink and the successive peak of the time-integrated DLV signal or between a peak and the successive sink. b Spectra of accelerations $\left(a_{\mathrm{vc}}\right)$ and dislocations $\left(D_{\mathrm{vc}}\right)$ of the comb of the experimental $A$. dorsata nest in the arousal and quiescence phases of experiments: ordinate, relative numbers ${ }_{\text {rel }} N_{\mathrm{vc}}$ of vibration cycle $(v c)$ intervals of the respective class value $\left(D_{\mathrm{vc}}\right)$; abscissa, ten classes of dislocations $D_{\mathrm{vc}}$ per cycle of comb vibration. Full circles and vertical bars give the means \pm SEMs. Black lines regression functions of the means: $y=c e^{x d}$; with $y={ }_{\mathrm{rel}} N_{\mathrm{vc}} ; x=D_{\mathrm{vc}}$; $R^{2}>0.94 ; N_{\mathrm{vc}}=12,686$. The green area refers to supra-threshold $\left(D_{\mathrm{vc}}>\right.$ $8.97 \mu \mathrm{m}$ per $T_{\mathrm{vc}}$, after Sandeman et al. 1996) dislocation amplitudes which made up $51.1 \%$ of cases (accessory diagram on the right)

al. 1993; Roces and Tautz 2001; dancing honey bees: Michelsen et al. 1986; Kirchner 1993; Tautz et al. 1996; Nieh and Tautz 2000; Hrncir et al. 2006), whereas the individual insects' pounding, beating or knocking on a substrate are utilized as the sources of mechanical energy.

Honeybees contrast herein with other vibrationproducing arthropods insofar as they utilise the comb as a substrate, which is built by the community itself, to which they directly cling for transmitting their communicative signals (Nieh and Tautz 2000). However, the shimmering process of giant honeybees and its relationship to comb vibration is different to the mechanical activities in the Western honeybees (Nieh and Tautz 2000). In giant honeybees, the shimmering-active individuals are positioned on the surface of the bee curtain. They have several layers of colony members underneath, which separate them from direct access to the comb and dampen the direct energy transfer from surface to comb. Nevertheless, the data presented in this paper provide evidence that the shimmering action yields sufficient power to drive the comb into measurable magnitude of vibration (Figs. 4, 5, 6, and 7). 
Testing the colony-intrinsic information hypothesis in giant honeybees

In this paper, we provide first evidence that shimmering behaviour (Kastberger et al. 2011a, b, 2012, 2013) of giant honeybees may essentially contribute to intra-colonial communication. The findings may support the colony-intrinsic information hypothesis (Kastberger et al. 2008) which assumes that shimmering has the potential to signal the momentary state of colony defence to the entire community, directing information to all curtain bees, even to those which have not actively participated in the wave. The concerted power of hundreds of shimmering-active surface bees conveys information through the multiple curtain layers. The centrally located comb in a giant honeybee nest is here the only element which does have the capacity of transmitting mechanical energy across the nest, in particular from the threatened to the contra-lateral, non-threatened side. This colony-intrinsic information hypothesis also addresses that both behaviours, shimmering and comb-building, may have customized themselves in relation to each other in the course of evolution, resulting in a cross-linked fine-tuning of their physical properties. Giant honeybees could herein serve as a prominent example for the performance of information transfer among colony members (summarised for arthropods by Evans et al. 2007 and more generally by Alcock 2005).

However, there is still an essential question which begs for an answer in future work: Would this sort of mechanoreceptive stimulation across the comb as provoked in shimmering waves actually bias or even benefit curtain bees on the non-threatened side? Although the data of the present paper leave this aspect untouched and cannot clarify this, we nevertheless back up the possibility and importance of comb-borne vibrations for colony-intrinsic communication by enlisting relevant physical properties of giant honeybee nests which are specifically affected by shimmering.

Mechanical requirements enabling colony-intrinsic communication

Vibrations of the comb during shimmering exhibited a basic frequency of slightly over $2 \mathrm{~Hz}$. They were excited by the natural repetition rate of the shimmering waves at slightly $<1 \mathrm{~Hz}$. This finding demonstrates independence between both frequencies which is an attribute for an obvious property of resonance of the comb. It is the nature of resonant systems (Nave 2001) to respond to external periodic influences, whereas the driven system tends to respond to frequency components of the external forces, which are close to and preferably slightly below the respective frequency bands (Nave 2001), and also to ultimately settle down to a performance determined by the driving force. The empirical data prove here the comb as an oscillator
(Figs. 4, 5, and 6) and the shimmering activity as the force which drives the comb at half of its basic frequency band. Furthermore, the comb vibrations approached zero in a short exponentially decaying sinusoid function (Fig. 4d), which expresses under-damping of a potentially harmonic oscillator (Nave 2001). In this respect, it is quite remarkable that the diffuse forces produced during mass flight activity (Kastberger et al. 1996) affect the comb at its possibly first harmonic component at $6 \mathrm{~Hz}$. These physical properties of the comb have been exemplified in the experimental nest but may happen in similar performance (possibly at slightly different frequency bands) in other giant honeybee nests of different sizes or ages.

These mechanical features of the vibrations, measured at the comb, and the driving forces of shimmering waves or of mass flight activity (Fig. 5) lead to two different, not exclusive, views of driven oscillator models explaining the compound physical system of an $A$. dorsata nest in general: it may behave as a physical pendulum or/and as an elastic mechanical plate (Fig. 8a). The question into which model was most fitting to the empirical data would have significance on the extent to which mechanical signals could be transmitted across the bee curtain.

Matching the empirical data with the physical pendulum theory A typical giant honeybee (A. dorsata) nest, alike the experimental nest used for this investigation, would display a mass of $M_{\mathrm{c}}>30 \mathrm{~kg}$ with a vertical extension of $L_{\mathrm{c}}>50 \mathrm{~cm}$. If excited as a physical pendulum with a typical torque force of shimmering of $F_{\mathrm{sh}}<1 \mathrm{~N}$ (Eqs. 1 and S3b), it may swing around the pivotal axis at its specific frequency $\left(\omega_{\mathrm{c}} \approx 2 \mathrm{~Hz}\right)$ with small angular displacements $\left(\ominus_{\mathrm{c}}<0.5^{\circ}\right)$ and a moment of inertia $I_{\mathrm{c}}($ Eqs. S1a and $\mathrm{S} 3 \mathrm{~s})$ which ranges between $I_{\mathrm{c}}=$ $0.55 \mathrm{~kg} / \mathrm{m}^{2}\left(M_{\mathrm{c}}=30 \mathrm{~kg}\right)$ and $I_{\mathrm{c}}=0.90 \mathrm{~kg} / \mathrm{m}^{2}\left(M_{\mathrm{c}}=50 \mathrm{~kg}\right)$.

In the experimental nest, we proved the coincidence between the empirical data and the physical pendulum model in the work domain twofold (Fig. 8b): under a linear approximation $\left(W_{\mathrm{D}}\right.$, Eq. $\left.\mathrm{S} 2\right)$ and under the rotational $\left(\tau_{\mathrm{c}}\right.$, Eq. S3) concept. The work $W_{\mathrm{D}}$ on the mass of the comb during one half of a vibration cycle is defined (Eq. S2b) by the product of the dislocating force $F_{\mathrm{D}}$ in the model nest $\left(M_{\mathrm{c}}=50 \mathrm{~kg} ; L_{\mathrm{c}}=30 \mathrm{~cm}\right.$; measurement position centre) and the empirically determined measures of its basic pendulum cycle (Eq. S2, with $T_{\mathrm{c}}=0.4638 \mathrm{~s}$; see Fig. 4b, d) under small dislocations $\left(D_{\mathrm{c}}=L_{\mathrm{c}} \times \sin \ominus_{\mathrm{c}}<10 \mu \mathrm{m}\right)$.

The rotational aspect of the pendulum model is quantified by the torque $\left(\tau_{\mathrm{c}}\right)$ of the comb (Eqs. S3 and S5) and considers the empirically estimated driving force $F_{\text {sh }}$ (which is set up by the cohorts of shimmeringactive bees at the surface of the nest; Eq. 5), the length of the pendulum rod (with $L_{\mathrm{c}}=30 \mathrm{~cm}$, as represented by the distance between the pivotal axis and the measurement 

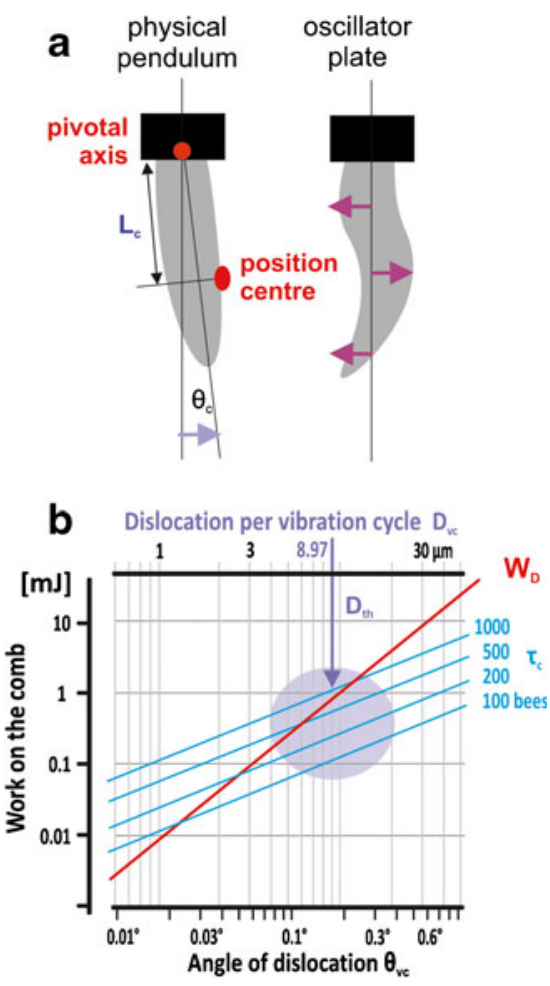

Fig. 8 How empirical data match the pendulum dislocation theory in the experimental $A$. dorsata nest. a Sketches of the comb of an $A$. dorsata nest as a physical pendulum and as an oscillator plate. Dislocation angle $\left(\ominus_{c}\right)$ of the comb, distance between the pivotal axis and the position centre as a substitute for the pendulum length $L_{\mathrm{c}}$. b Lookup table of work on the comb against dislocation length $\left(D_{\mathrm{vc}}\right)$ and dislocation angle $\left(\ominus_{\mathrm{vc}}\right)$ per cycle of the comb vibration at position centre $\left(L_{\mathrm{c}}=30 \mathrm{~cm}\right)$. The red line gives the work $W_{\mathrm{D}}(\mathrm{Eq} .2 \mathrm{~b})$ which considers the dislocation and the acceleration in the half cycle of a vibration $\left(T_{\mathrm{vc}} / 2\right)$; the blue lines give the torque (Eq. 3 ) estimated under four conditions of $F_{\mathrm{sh}}$ when 100-1,000 surface bees act synchronized but asymmetrically on one side of the comb during shimmering. The vertical arrow $D_{\text {th }}$ gives the threshold dislocation estimated after Sandeman et al. (1996) for a vibration of $2 \mathrm{~Hz}$. It is illustrated that both work values match for the threshold dislocation in the small area denoted by the violet full circle

position centre) and the empirically determined angle of the natural vibration cycle $\ominus_{\mathrm{c}}$ :

$\tau_{\mathrm{c}}=L_{\mathrm{c}} F_{\mathrm{sh}} \sin \ominus_{\mathrm{c}}[$ Joule $]$

As result, the torque lines (Fig. $8 \mathrm{~b}$ ) of a variable number of shimmering-active bees $\left(N_{\text {bees }}=100-1,000\right)$ show gentler slopes than the $W_{\mathrm{D}}$ curve. We assume that the best correspondence of both work models $\left(W_{\mathrm{D}}, \tau_{\mathrm{c}}\right)$ is given at the crossing points of the functions which occurred at dislocations of $\ominus_{\mathrm{c}}<0.2^{\circ}$, correspondingly $D_{\mathrm{c}}<12 \mu \mathrm{m}$, per vibration cycle. Remarkably, this crucial dislocation values coincide with that of the sensory threshold of honeybees $\left(D_{\mathrm{th}}=\right.$ $8.97 \mu \mathrm{m})$ as estimated after Sandeman et al. (1996) for $2 \mathrm{~Hz}$ and refer, theoretically, to a driving force produced by a shimmering wave of $N_{\text {bee }}=500-1,000$ active bees (Fig. 8b).
Requirements for acceptance of the pendulum hypothesis This match of theoretical and empirical data in the work domain supports the view that a giant honeybee nest shows the performance of a physical pendulum (see Supplementary Text 1), with the shimmering activity of surface bees as its driving force. However, for the acceptance of this (shimmering-drives-the-nest-as- $a$-) pendulum hypothesis, the empirical data of the comb have to meet the further three predictions: First, the natural frequency $\left[\omega_{\mathrm{c}}\right]$ of the real comb should match with the mathematically expected natural frequency of a physical pendulum of similar shape $\left(M_{\mathrm{c}}, L_{\mathrm{c}}\right)$; second, the real comb should show the same natural frequency along its full 'rod' length $\left[L_{\mathrm{c}}\right]$; and third, the amplitudes of the oscillations $\left(\Theta_{\mathrm{c}}, D_{\mathrm{c}}\right)$ should show a gradient according to their distance from the pivotal axis.

The measurements confirm these expectations: First, the basic ('natural') period of the comb $\left(T_{\mathrm{c}}=0.4682 \pm 0.0106 \mathrm{~s}\right.$; $n_{\mathrm{s}}=23$ sessions $)$ of the experimental nest $\left(M_{\mathrm{c}}=40 \mathrm{~kg}, I_{\mathrm{c}}=\right.$ $0.7 \mathrm{~kg} / \mathrm{m}^{2}$ ) under the regime of shimmering waves match the theoretical predictions (see Eq. S1a). Interestingly, under mass flight activity, the vibrations occur at $6 \mathrm{~Hz}$ which demonstrates that the comb also functions as an elastic plate. Second, the basic periods of the comb vibration differed only slightly between the main measurement positions (centre: $T_{\mathrm{c}}=0.4798 \mathrm{~s} ;$ att: $T_{\mathrm{c}}=0.4503 \mathrm{~s} ; P=0.1312, t$ test). And third, the data document a gradient in the dislocation amplitude $D_{\mathrm{c}}$ from the attachment zone down to the lower rim in two aspects: the comb displacements ${ }_{\text {rel }} D_{\mathrm{c}}$ were larger at position centre than at position att (Fig. $6 \mathrm{~d}$; $P=0.038$, Eqs. $2 \mathrm{a}, 2 \mathrm{~b}$, and $2 \mathrm{c})$ and the occurrence of larger displacements was higher at position centre $(P<0.001, t$ test $)$ than at position att. These latter results were achieved in the frame-based (Fig. S1c-e) and cycle-based (Fig. 8b) filtered data of comb vibrations and are also documented in the spectra (Fig. 5).

Matching the empirical data with the alternative elastic mechanical plate model The second approach to explain the swinging comb of a giant honeybee nest under the regime of shimmering is to compare it with a plane elastic structure oscillating at its natural resonance frequency. This view is obvious because the centrally positioned comb is built of wax stiffed by the watery cell contents of honey or jelly, which may give some local elasticity. This structure can be compared with Apis mellifera hives (Sandeman et al. 1996) where pieces of comb even bounded by frames on all sides still carry a low-frequency signal of about $15 \mathrm{~Hz}$, while higher-frequency displacements of $>60 \mathrm{~Hz}$ could not be detected four cells away from the source (Sandeman et al. 1996). Low-frequency signals in Western honeybees detected from the comb site are known for producing a grooming invitation dance, when workers stand stationary vibrating their bodies from side to side at a frequency of 
$4 \mathrm{~Hz}$ for $10 \mathrm{~s}$ (Land and Seeley 2003). It is also known that vibrations are transmitted in the plane of the comb face (Michelsen et al. 1986) when produced by 'beggar' bees which press their thoraces down onto the comb while producing a $320-\mathrm{Hz}$ vibration by the thoracic musculature. Here, displacements of up to $1.5 \mu \mathrm{m}$ at right angles to the plane of the comb face can be measured even a few centimetres, but not more, away from those bees. Such traits in A. mellifera combs accord with the physical properties of an elastic mechanical plate which acts as a highly damped oscillator.

In contrast to A. mellifera, giant honeybees produce the oscillation of the central comb by the upstrokes of the abdomens of shimmering bees which happens synchronized and cascaded predominantly at the nest surface. These mechanical waves propagate across the nest but are damped down by the multiple layers of the bee curtain before they reach the comb. The elastic mechanical plate hypothesis predicts here that the comb would oscillate at its local natural frequency bands, which may vary regarding the consistence of comb cells (Sandeman et al. 1996). Furthermore, the locally provoked vibrations should show displacements at different positions of essentially similar magnitude.

This aspect of an elastic mechanical plate is supported by the spectral properties of the comb of the experimental nest, in particular because of the occurrence of two main frequency bands, one slightly above $2 \mathrm{~Hz}$ and the other at $6 \mathrm{~Hz}$ (Fig. 6a-e). These two bands happened irrespective whether the nest was investigated under quiescent or arousal conditions (provoked by shimmering waves or by mass flight activity) and whether the vibrations had been detected near the attachment zone (position S1; Fig. 1) or near the lower rim zone (position S3). It also seems as if mass flight activity provoked vibrations at the higher frequency band rather than at the lower one, whereas shimmering waves mainly drove the comb at the lower frequency band. Although the data displayed in Fig. 5 were ephemeral, they document the stable character of both frequency bands, in particular at small vibration amplitudes.

\section{Magnitude of mechanoreceptive signalling}

The behavioural traits of the mechanical oscillations at the comb generated by shimmering raise two further questions: First, do the vibrations gain sufficient power to achieve signal value; in other words, are they sufficient to stimulate the curtain bees on the side contra-lateral to the threatened one? If the shimmering process has evolved (in addition to its anti-predatory goals, cf. Kastberger et al. 2008) to enforce colony-intrinsic communication, it should accelerate the comb by the wave-like flashes at intensities which exceed the sensory threshold of honeybees. In A. mellifera, the most sensitive frequencies were found (Sandeman et al. 1996) between 30 and $100 \mathrm{~Hz}$ with threshold displacements $\left(D_{\mathrm{th}}\right)$ of $2 \mu \mathrm{m}$ and a threshold sensitivity of $D_{\mathrm{th}}=6.2 \mu \mathrm{m}$ at $10 \mathrm{~Hz}$. Extrapolation of the empirical data (Sandeman et al. 1996) to lower frequencies results in $D_{\mathrm{th}}=8.97 \mu \mathrm{m}$ for a $2-\mathrm{Hz}$ vibration which corresponds to a threshold acceleration of $0.0355 \mathrm{~mm} / \mathrm{s}^{2}$.

In $A$. dorsata nests, the vibration spectrum of the central comb, based on a cycle-related analysis during shimmering waves, revealed supra-threshold displacements of more than $9 \mu \mathrm{m}$ per natural cycle of comb vibrations in $51.08 \%$ of the observation time (Fig. 7), but still $10 \%$ of vibration cycles had the fivefold value of $45 \mu \mathrm{m}$ and, therefore, accelerate the comb by more than $0.2 \mathrm{~mm} / \mathrm{s}$. These vibrations were only present under ongoing shimmering activity but not after its termination and differed significantly in their dislocation spectra between the recording positions (centre, att) in the arousal phase of the experiments.

This means that shimmering flashes do have the potential to provoke comb vibrations as supra-threshold cues for the curtain bees. Due to the pendulum effect, we can expect that factually all curtain bees are able to sense this mechanical signal irrespective of their engagement in shimmering, practically in all layers of the curtain, and on both sides of the comb, but with two restrictions: first, these colony members who are positioned at the lower portions of the bee curtain would perceive the comb vibrations stronger than those positioned near the attachment zone; and second, the loose coupling of the bee curtain with the comb expectedly damps the impact of comb oscillations, in particular for the outer layers of curtain bees. Therefore, the cohorts near the comb could sense such vibrations more strongly than colony members at the outer layers of the bee curtain.

Summarizing, the findings not only support the pendulum's hypothesis for the impact of the pulsed forces of shimmering on the comb of giant honeybee nests but also show that the elastic mechanical plate hypothesis matches the conditions under more stochastic forces such as under the conditions of mass flight activity (Kastberger et al. 1996).

\section{Conclusions}

A giant honeybee (A. dorsata) nest comprises, from a physics viewpoint, a central comb as a stiff plate, attached to a solid substrate and covered by the multilayered bee curtain. Shimmering generates repetitive wave-like flashes in the mechanical domain and provokes vibrations which operate the comb as a driven under-damped oscillator. The repetition rate of shimmering waves $\left(F_{\mathrm{sh}}=0.957 \mathrm{~Hz}\right)$ is $\approx 1 \mathrm{~Hz}$ lower than the basic frequency of the comb $\left(f_{\mathrm{c}}=2.112 \mathrm{~Hz}\right)$, which determines the powering of the comb as a driven oscillator. The oscillation properties of the comb match the 
model of a mechanical pendulum under the pulses of shimmering waves, whereas under the much weaker and diffuse forces of mass flight activity or even under general quiescence of the nest, the comb shows with two frequency bands, a virtually harmonic property indicative for the performance as an elastic plate. Shimmering waves deliver forces upon the comb above the sensory threshold of honeybees, sufficiently strong for being perceived by worker bees throughout the bee curtain. The pendulum principle may provide mechanical information to those members of the bee curtain who are assembled nearer to the lower nest in the rim zone, while the elastic plate properties mediate shimmering-provoked vibration to those members who are in direct contact with the comb. The findings support the colony-intrinsic communication hypothesis that shimmering serves as a fast way to inform the members of the bee curtain about the momentary defensive state of the nest.

Acknowledgments We thank Dr. Madhu Singh, Dr. S.M. Man, Dr. R. Thapa and Dr. M. B. Gewali from Tribhuvan University, Kathman$\mathrm{du}$, Nepal, for their support regarding logistics, Klaus Maresch for his help with handling of the bees in Chitwan, Horst Bischof and Matthias Ruether from the Technical University of Graz, Austria, for their support with the development of the specific software used for this study and Gerald Eder, University Graz, for the basic evaluation of the primary data in his Bachelor's thesis.

Funding The study has been supported by the Austrian Science Fund (FWF Project P 20515-B16). The funders had no role in the study design, data collection and analysis, decision to publish or preparation of the manuscript.

Ethics statement The government office of the Tribhuvan University (Centre for International Relations) of Kathmandu (Nepal) certified the research expedition under the title 'Study on the behaviour of the giant honeybees: observations and recording of behaviours at the nesting site in the Chitwan district of Nepal 2009 and 2010'.

Open Access This article is distributed under the terms of the Creative Commons Attribution License which permits any use, distribution, and reproduction in any medium, provided the original author(s) and the source are credited.

\section{References}

Alcock J (2005) Animal behaviour, 8th edn. Sinauer Associates Inc., Massachusetts

Carne PB (1962) The characteristics and behaviour of the sawfly Perga affinis affinis Hymenoptera. Aust J Zool 10:1-34

Claridge MF (1985) Acoustic signals in the Homoptera: behavior, taxonomy and evolution. Annu Rev Entomol 30:297-317

Cocroft RB (1996) Insect vibrational defence signals. Nature 382:679_ 680

Cocroft RB, Rodriguez RL (2005) The behavioural ecology of insect vibrational communication. Bioscience 55:323-334
DeVries PJ, Cocroft RB, Thomas J (1993) Comparison of acoustical signals in Maculinea butterfly caterpillars and their obligate host Myrmica ants. Zool J Linn Soc 49:229-238

Evans TA, Inta R, Lai JCS, Lenz M (2007) Foraging vibration signals attract foragers and identify food size in the drywood termite, Cryptotermes secundus. Insect Soc 54:374-382. doi:10.1007/ s00040-007-0958-1

Fletcher LE, Yack JE, Fitzgerald TD, Hoy RR (2006) Vibrational communication in the cherry leaf roller caterpillar Caloptilia serotinella (Gracillarioidea: Gracillariidae). J Insect Behav 19:1-18

Grasse P (1959) La reconstruction du nid et les coordinations inter-individuelles chez Bellicostitermes natalensis et Cubitermes. sp. La theorie de la stigmergie: Essai d'interpretation du comportement des termites constructeurs. Insect Soc 61:41-80

Hartbauer M (2010) Collective defense of Aphis nerii and Uroleucon hypochoeridis (Homoptera, Aphididae) against natural enemies. PLoS One 5(4):e10417. doi:10.1371/journal.pone.0010417

Hrncir M, Barth FG, Tautz J (2006) Vibratory and airborne sound signals in bee communication Hymenoptera. In: Drosopoulos S, Claridge MF (eds) Insect sounds and communication: physiology, behaviour, ecology and evolution. CRC/Taylor and Francis, Boca Raton, pp 421-436

Jones PL, Page RA, Hartbauer M, Siemers BM (2011) Behavioral evidence for eavesdropping on prey song in two Palearctic sibling bat species. Behav Ecol Sociobiol 65:333-340. doi:10.1007/ s00265-010-1050-9

Kastberger G (1999) The magic trees of Assam - documentary film about the biology of the giant honeybee Apis dorsata. National Geographic, ZDF, ORF \& epo-film, Wien

Kastberger G, Sharma DK (2000) The predator-prey interaction between blue-bearded bee-eaters (Nyctyonis athertoni) and giant honeybees (Apis dorsata). Apidologie 31:727-736

Kastberger G, Winder O, Hoetzl T, Raspotnig G (1996) Behavioural features of a periodic form of massed flight activity in the giant honeybee Apis dorsata. Apidologie 27:381-395

Kastberger G, Schmelzer E, Kranner I (2008) Social waves in giant honeybees repel hornets. PLoS One 3(9):e3141. doi:10.1371/ journal.pone. 0003141

Kastberger G, Weihmann F, Hoetzl T (2010) Complex social waves of giant honeybees provoked by a dummy wasp support the special-agent hypothesis. Commun Integr Biol 3(2):179-180

Kastberger G, Weihmann F, Hötzl T (2011a) Self-assembly processes in honeybees: the phenomenon of shimmering. In: Hepburn R, Radcliff S (eds) Honeybees of Asia.. ISBN 978-3-642-16421-7 (Print); 978-3-642-16422-4 (Online)

Kastberger G, Maurer M, Weihmann F, Ruether M, Hötzl T, Kranner I, Bischof H (2011b) Stereoscopic motion analysis in densely packed clusters: 3D analysis of the shimmering behaviour in giant honey bees. Front Zool 8:3, http://www.frontiersinzoology.com/ content $/ 8 / 1 / 3$

Kastberger G, Weihmann F, Hötzl T, Weiss SE, Maurer M (2012) How to join a wave: decision-making processes in shimmering behavior of giant honeybees (Apis dorsata). PLoS One 7(5):e36736. doi:10.1371/journal.pone.0036736

Kastberger G, Weihmann F, Hötzl T, Weiss SE, Maurer M (2013) Speeding up social waves. Propagation mechanisms of shimmering in giant honeybees. Front Zool (in press)

Kirchner WH (1993) Acoustical communication in honeybees. Apidologie 24:297-307

Land BB, Seeley TD (2003) The grooming invitation dance of the honey bee. Ethology 110:1-10. doi:10.1046/j.1439-0310.2003.00947.x

Michelsen A, Kirchner WH, Lindauer M (1986) Sound and vibrational signals in the dance language of the honeybee, Apis mellifera. Behav Ecol Sociobiol 18:207-212 
Nave CR (2001) Hyperphysics. Department of Physics and Astronomy, Georgia State University, Atlanta, http://hyperphysics.phyastr.gsu.edu/hbase/pendp.html\#c2

Nieh JC, Tautz J (2000) Behaviour-locked signal analysis reveals weak 200-300 $\mathrm{Hz}$ comb vibrations during the honeybee waggle dance. J Exp Biol 203:1573-1579

Oldroyd BP, Wongsiri S (2006) Asian honey bees. Harvard University Press, Cambridge

Peake TM (2005) Eavesdropping in communication networks. In: McGregor PK (ed) Animal communication networks. Cambridge University Press, Cambridge, pp 13-37

Roces F, Tautz J (2001) Ants are deaf. J Acoust Soc Am 109:380-382

Roces F, Tautz J, Hoelldobler B (1993) Stridulation in leaf-cutting ants-short-range recruitment through plant-borne vibrations. Naturwissenschaften 80:521-524

Ruttner F (1988) Biogeography and taxonomy of honeybees. Springer, Berlin
Sandeman DC, Tautz J, Lindauer M (1996) Transmission of vibration across honeycombs and its detection by bee leg receptors. J Exp Biol 199:2585-2594

Schmelzer E, Kastberger G (2009) Special agents' trigger social waves in giant honeybees (Apis dorsata). Naturwissenschaften 96:14311441. doi:10.1007/s00114-009-0605-y

Seeley TD, Seeley RH, Akratanakul P (1982) Colony defence strategies of the honeybees in Thailand. Ecol Monogr 52:43-63

Tautz J, Rohrseitz K, Sandeman DC (1996) One-strided waggle dance in bees. Nature 382:32

Weihmann F, Hötzl T, Kastberger G (2012) Training for defence? From stochastic traits to synchrony in giant honeybees (Apis dorsata). Insects 3(3):789-820. doi:10.3390/insects3030789

Yack JE, Smith ML, Weatherhead PJ (2001) Caterpillar talk: acoustically mediated territoriality in larval Lepidoptera. Proc Natl Acad Sci USA 98:11371-11375 